\title{
Espacios para el arte en un edificio moderno. Móvil y murales I Cincinnati's Terrace Plaza
}

\author{
Andrea Parga \\ Universitat Politècnica de Catalunya \\ andrea.parga@upc.edu
}

RESUMEN: El proyecto del Terrace Plaza en Cincinnati fue desarrollado de un modo particular por la firma de arquitectos Skidmore, Owings \& Merrill (SOM) entre 1945-1948. El edificio reunió grandes almacenes, oficinas, bares, restaurantes y apartamentos en una única y singular intervención; numerosos recursos operativos sumaron matices importantes al complejo ensamblaje. Los niveles elevados presentaron interiores cuidadosamente diseñados con vistas hacia el derredor, y la extensión de las salas gastronómicas hacia las terrazas mejoró la calidad de estos ámbitos abiertos en altura. También fue significativa la forma en que el arte y el entorno construido se entrelazaron a través de eventos espaciales orquestados con esmero. Revistas especializadas y documentos de archivo evidencian el papel que los artistas Calder, Steinberg, Davis y Miró desempeñaron en la arquitectura del edificio. El ensayo se centra en el sistema espacial del hotel y, en específico, en la interacción del arte y el proyecto arquitectónico.

PALABRAS CLAVE: Terrazas panorámicas; Relación arte-arquitectura contemporáneos; Arte corporativo; Arquitectura moderna; Skidmore, Owings \& Merrill.

\section{Spaces for Art in a Modern Building. Mobile and Murals | Cincinnati's Terrace Plaza}

ABSTRACT: The Terrace Plaza project in Cincinnati was developed in a particular way by the firm of architects Skidmore, Owings \& Merrill (SOM) between 1945-1948. It comprised department stores, offices, bars, restaurants, and housing units, all together in a single and unique structure; several operational resources added important distinctions to this complex assembly. The elevated levels showed carefully designed interiors, expanding their views towards the environs. The extension of the gastronomic halls to the terraces enhanced the quality of these elevated open courtyards. The way in which art and the constructed surrounds of the building intertwine through carefully orchestrated spatial events was also meaningful. Contemporary magazines and other archival documents are evidence of the role that artists Calder, Steinberg, Davis and Miró played in the building's architecture. This essay focuses on the hotel spatial system and, specifically, on the interaction of art and the architectural project.

KEYWORDS: Panoramic Terraces; Contemporary Art-Architecture Relationship; Corporate Art; Modern Architecture; Skidmore, Owings \& Merrill.

Recibido: 23 de febrero de 2020 / Aceptado: 25 de junio de 2020.

El Terrace Plaza fue el primer hotel diseñado por SOM${ }^{1}$ y uno de los primeros hoteles modernos en los Estados Unidos. Se accedió a su vestíbulo, ubicado en la octava planta, mediante veloces ascensores que partieron desde el acceso en la calle. Dos grandes almacenes ocuparon originalmente las siete plantas de base. El último nivel, que albergó un pequeño restaurante gourmet, ofreció vistas panorámicas de la ciudad. SOM diseñó los interiores y los accesorios de este restaurante y encargó un mural a Joan Miró como punto focal de su única sala. Obras de otros artistas fueron incluidas en el proyecto arquitectónico del hotel; un móvil de Calder colgaba en el vestíbulo y un mural de Saul Steinberg decoraba el restaurante principal².

Cómo citar este artículo: PARGA, Andrea, «Espacios para el arte en un edificio moderno. Móvil y murales | Cincinnati's Terrace Plaza», Boletín de Arte-UMA, n. 42 , Departamento de Historia del Arte, Universidad de Málaga, 2021, pp. 175-187, ISSN: 0211-8483, e-ISSN: 2695-415X, DOI: http://dx.doi.org/10.24310/BoLArte.2021.vi42.11035 

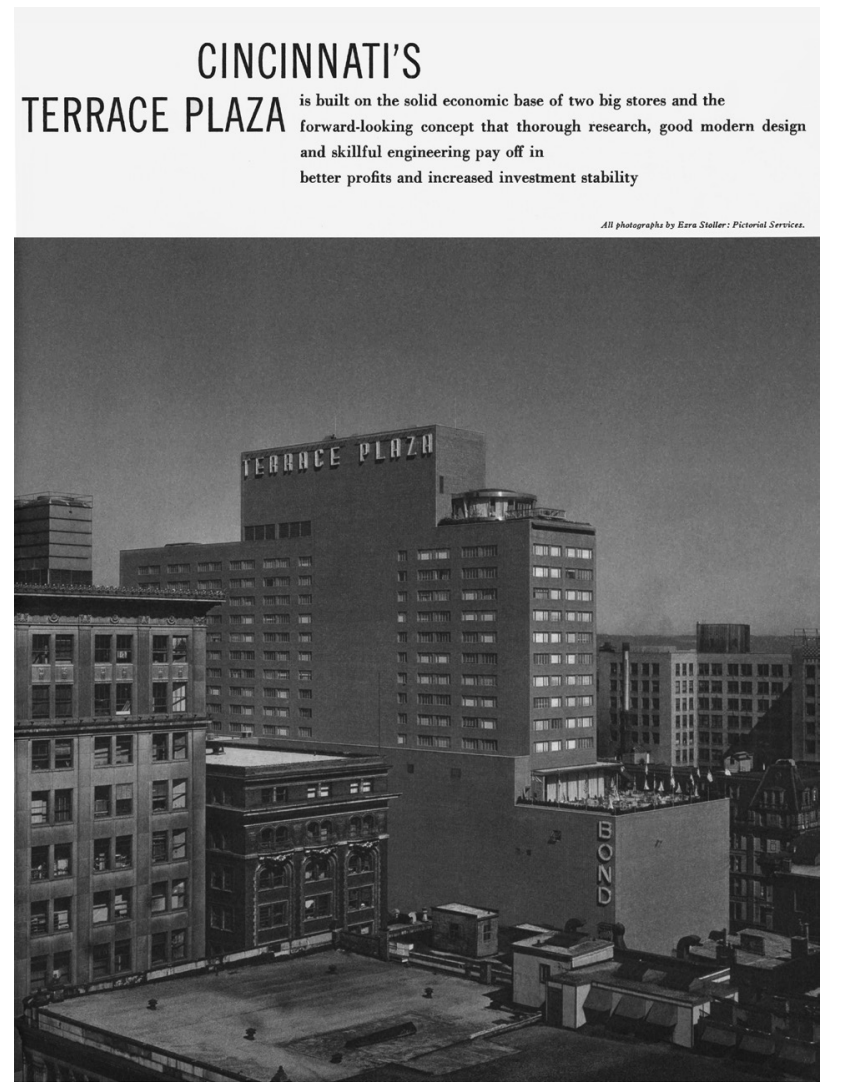

1. Portada de la revista Architectural Forum en la que se muestra una imagen del conjunto de edificios del downtown que rodean las terrazas de la octava y vigésima planta del Terrace Plaza Hotel. Fuente: «Cincinnati's Terrace Plaza» (1948, diciembre), Architectural Forum, Nueva York. Portada (fotografía: Ezra Stoller, Pictorial Services)

De esta forma Skidmore, Owings \& Merrill nos presentan en la actualidad el proyecto que la oficina de SOM New York desarrolló en Cincinnati entre 1945-1948. La conexión con los ritmos de desplazamiento urbano a través de una eficaz circulación vertical permitió el avance de los primeros esquemas de la oficina para la configuración del edificio. La batería de ascensores de alta velocidad habilitó la aparición del vestíbulo a ocho plantas de la cota cero, un conjunto de restaurantes en niveles elevados y el disfrute de las terrazas en altura. Obras de artistas contemporáneos completaron el diseño de los espacios comunes del hotel.

Los promotores y entusiastas coleccionistas, John Emery y Ellsworth Ireland, eligieron a SOM atraídos por una propuesta que aprovechó el uso de los derechos aéreos sobre la cubierta de los grandes almacenes situados en el centro de la ciudad, y que configuró un edificio moderno con intención de integrar el arte en su interior. El hecho de que SOM acometía por primera vez el desarrollo de un hotel fue otra razón para la elección; este motivo cautivó a Emery, quien deseaba un proyecto fuera de serie. El encargo resultó clave para la firma ya que les permitió poner en marcha el trabajo interdisciplinario en equipo y de continua búsqueda de avance tecnológico que distinguiría sus propuestas [1].

En la primavera de 1945, Louis Skidmore y William S. Brown habían acabado el diseño esquemático para el hotel, fue entonces cuando pidieron la colaboración de Natalie de Blois, también arquitecta de la firma ${ }^{3}$. Ella culminó la tarea desde la oficina SOM New York; desarrolló los esquemas iniciales, organizó la estructura, resolvió las secciones y las elevaciones. Ben Baldwin fue contratado como diseñador de interiores en 1946, quien en poco tiempo se centró sólo en la terraza del octavo piso, desarrollando un espacio al aire libre con carácter semejante al de los jardines elevados del Rockefeller Center y a la dinámica de algunas azoteas habilitadas para actividades de ocio en ciertos hoteles de Nueva York [2]. Emery estaba abierto a la innovación en alojamientos, por lo que SOM fortaleció un equipo abocado a una novedosa solución ${ }^{4}$. La aparición del Terrace Plaza como uno de los primeros hoteles modernos en Estados Unidos en 1949, coincidió en el mismo año con la construcción de otros hoteles singulares en altura; la cadena hotelera Hilton dio el salto al Caribe Moderno y auspició un concurso en la isla de Puerto Rico para su sede en San Juan, de allí se incorporó entre centro de ciudad y primera línea de mar un hotel, el Caribe Hilton, que atendiendo a las peculiaridades de su emplazamiento rompió el protocolo de la ejecución habitual de los hoteles de la cadena ${ }^{5}$. Del mismo modo, y también en 1949, el arquitecto Rino Levi desarrolló un edificio que compatibilizó cine y hotel en una única propuesta, la solución dispuso las tres primeras plantas para las salas de proyección, resolvió con prismas limpios las restricciones de la normativa local y dispuso el restaurante principal en la última planta del hotel ${ }^{6}$, condiciones parecidas a las del proyecto en avance del Terrace Plaza.

Por ello, la exploración del artículo insiste en cómo el hotel en Cincinnati resultó una oportunidad para introducir un modo renovado de abordar el diseño arquitectónico. El objetivo apunta a comprender cómo el equipo interdisciplinar de la firma articuló los espacios comunes entre interior y exterior, sus sistemas de conexiones y la presencia del arte en un 
2. Jardín en la terraza del Hotel Montclair, Nueva York. Champán y bailes de tarde al aire libre. Fuente: Rota, Italo (2000), Not only Buildings, Milan

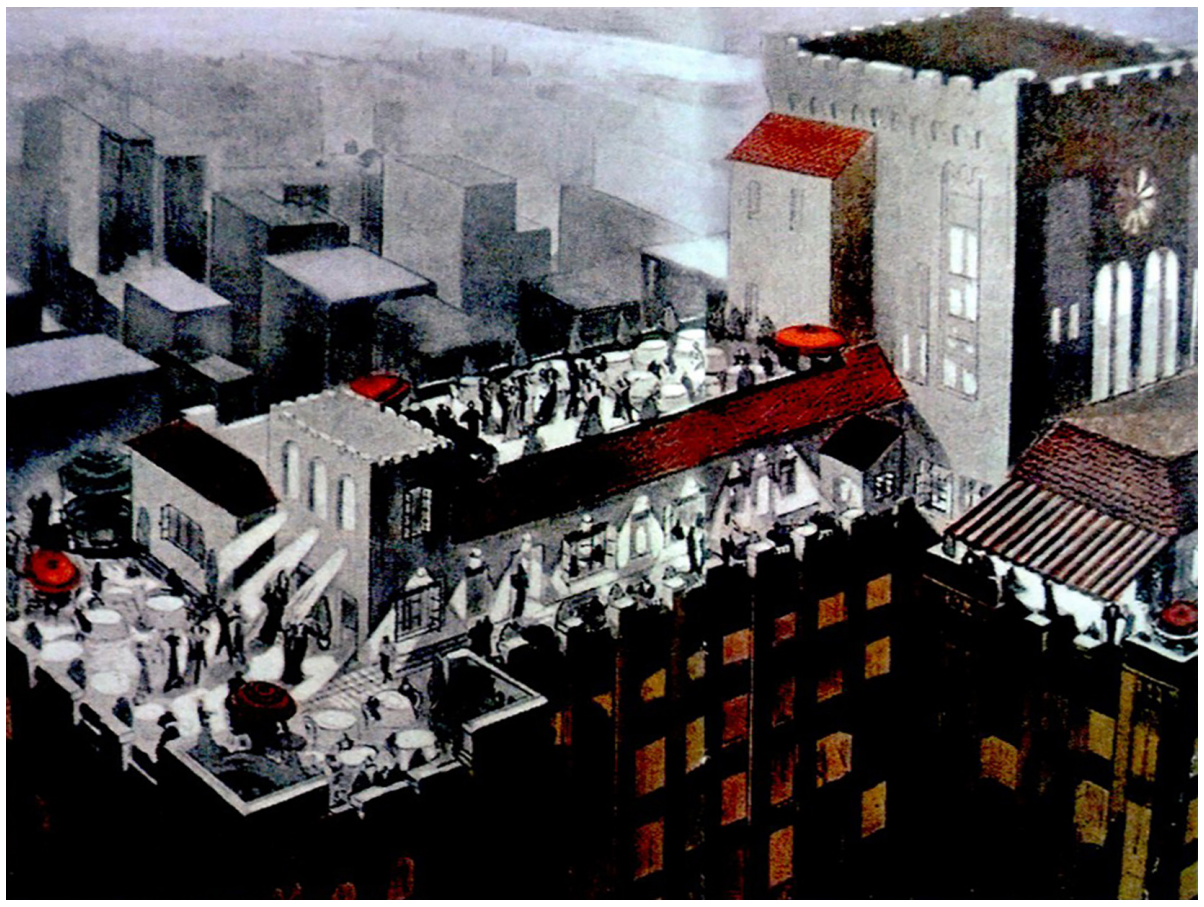

edificio inusual. Para ello se cuenta con las revistas de época Architectural Forum, que dieron seguimiento al proyecto, construcción y estado posterior del hotel. Este material se completa con el informe del Terrace Plaza Hotel presentado en junio de 2017 al National Register of Historic Places United States Department of the Interior. National Park Service. Cincinnati ${ }^{7}$. El seguimiento documental se muestra articulado en cuatro partes. La primera, "Emplazar en el aire», que atiende a la consideración de las terrazas panorámicas en los niveles octavo y vigésimo; la segunda, «Relaciones arriba, abajo y alrededor», que apunta a las vinculaciones entre las estancias colectivas que se promovieron en el interior del edificio; la tercera, «El papel de la obra de Calder, Steinberg, Davis y Miró», que se concentra en el significado de la inclusión de las obras de arte en los ámbitos comunes y de restauración; y la cuarta, "Atmósferas de arte y cristal», que se dedica a la reflexión sobre los ambientes que se lograron entre el arte, el uso del cristal en los límites de determinados espacios y las visuales que se ganaron hacia la ciudad. El estudio busca poner atención sobre las relaciones entre espacios, elementos y disciplinas que se introdujeron y probaron en el hotel y que han tenido continuidad y evolución en los trabajos subsecuentes de SOM.
Emplazar en el aire

El Rockefeller Center se ha hecho mundialmente famoso, no sólo por el diseño de sus edificios situados en varias manzanas del Midtown de la ciudad de Nueva York, si no por las relaciones excelentes entre los edificios y los espacios abiertos entre ellos ${ }^{8}$.

El complejo neoyorquino fue un lugar de recreo metropolitano poco común en la congestión del centro de Manhattan, proporcionó un oasis peatonal de distensión al aire libre. El uso de las azoteas significó la réplica de parte del solar en niveles superiores. El diseño de espacios públicos y colectivos a diez niveles sobre la planta baja, la duplicó en lo alto del emplazamiento original. La introducción de la vegetación creó un parque sobre las tres manzanas. Estas zonas verdes de jardines temáticos de esculturas, situadas en las cubiertas de los bloques bajos, resultaron las segundas áreas de expansión de las torres, fueron miradores sobre calles y avenidas (Parga, 2018: 46) [3].

El Terrace Plaza Hotel, al igual que el Rockefeller Center, también buscó integrar los espacios abiertos situados en co- 


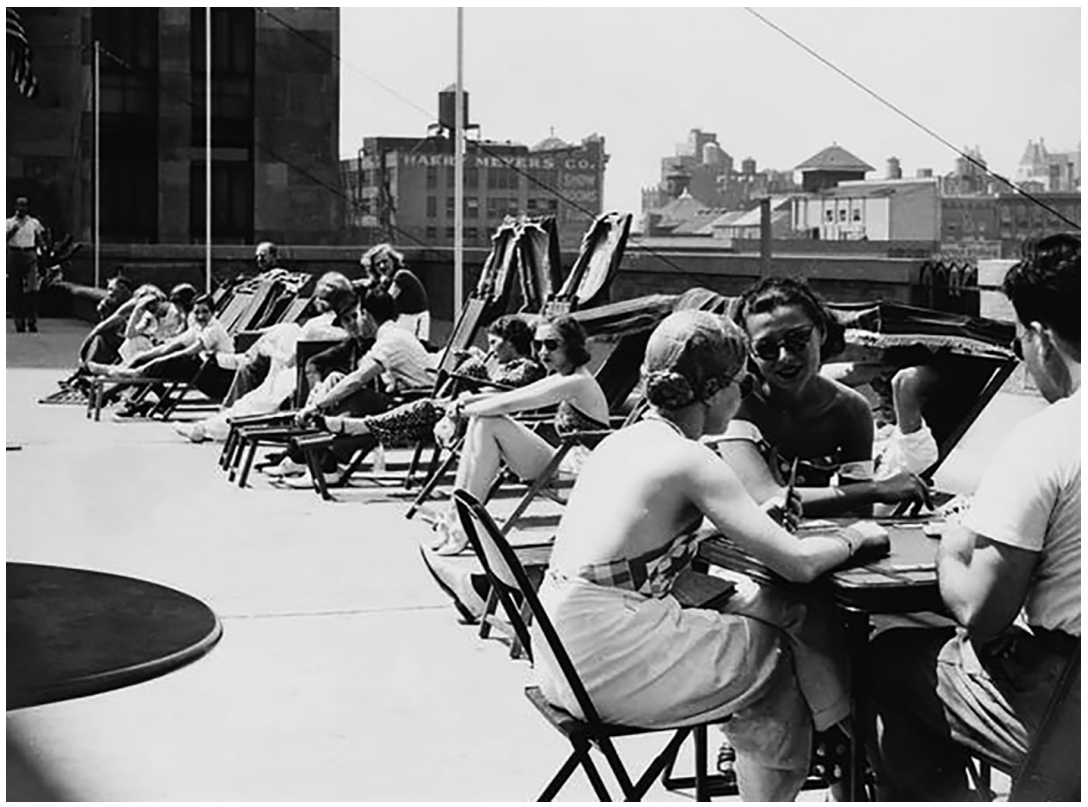

3. Terraza del Radio City Music Hall. 1260 Sixth Avenue. Rockefeller Center. Midtown, Nueva York, 1935 (fotografía: Wurts Bros). Fuente: Museum of the City of New York. $<$ https://collections.mcny.org/Collection/1260 Sixth Avenue. Radio City Music Hall. Roof, leisure time-24UFQEONATG.html> (fecha de consulta: 01-07- 2020) tas superiores; esto fue posible gracias al hábil manejo de las regulaciones de zonificación urbana de Cincinnati. El encargo requirió el encaje de un edificio de uso mixto en altura, que se incorporaría en el centro de la ciudad, en el 15 West Sixth Street; en un solar que ocupó la mitad norte de la manzana, abarcando West Sixth Street entre Vine Street y Race Street. Las normativas permitieron que la altura de la base fuera el doble de la medida del ancho de las calles circundantes, de aquí surgirían las 7 primeras plantas. Para continuar construyendo en la vertical, se cuidó de cumplir 1 pie $(0,30 \mathrm{~m})$ de retroceso por cada 4 pies $(1,21 \mathrm{~m})$ de elevación. Por tanto, para mantener volúmenes limpios, los arquitectos plantearon un ático de 50 pies $(15,24$ m) x 300 pies $(91,44$ m) en la cubierta del volumen inferior. La fachada del hotel en este punto se dispuso atrasada hacia el oeste desde su alineación al perímetro del solar, favoreciendo una terraza sobre Vine Street.

La innovación de diseño más llamativa, que surgió naturalmente de tener los grandes almacenes de base, fue la de subir el vestíbulo del hotel a la planta octava. Al considerar todos los retrocesos de zonificación requeridos a este nivel, los diseñadores obtuvieron una atractiva plaza en la azotea contigua al vestíbulo, elevada por encima del tráfico y los ruidos de la calle y equipada tanto para cenas de verano, como para patinaje sobre hielo en invierno ${ }^{9}$ [4]
Las directrices de la intervención en Cincinnati desvelaron el espíritu renovador de los proyectistas de SOM. En agosto de 1949, Architectural Forum publicó un artículo con la exposición de los ejes de trabajo de la firma. El hotel en Cincinnati materializó las ideas que expresó Nathaniel A. Owings en su discurso sobre el edificio ideal. La alocución de Owings se incluyó como colofón de la presentación de una estación de autobuses en el centro de Chicago. La voluntad de aprovechar las cubiertas de los volúmenes bajos que reproducen el perímetro del lote en cotas más altas sería recurrente en los proyectos de SOM:

En la cuarta planta, en la totalidad del solar, haremos un parque al aire libre con césped y árboles naturales, con piscinas y restaurantes. La entrada de nuestro edificio de oficinas se situará en ese nivel elevado. Escaleras mecánicas nos llevaran desde el estacionamiento de coches hasta el oasis verde ${ }^{10}$.

Con la voluntad de intervenir en ese sentido, la propuesta de Cincinnati atendió tanto a la escala propia del interior del hotel como a la escala del entorno de la ciudad a la que el edificio se incorporó; para ello, en el paso hacia las terrazas, se optó por el uso del cristal que brindaría la panorámica urbana desde la peculiar situación de sus espacios en altura. El paisajismo se sumó al desarrollo de la obra; se 


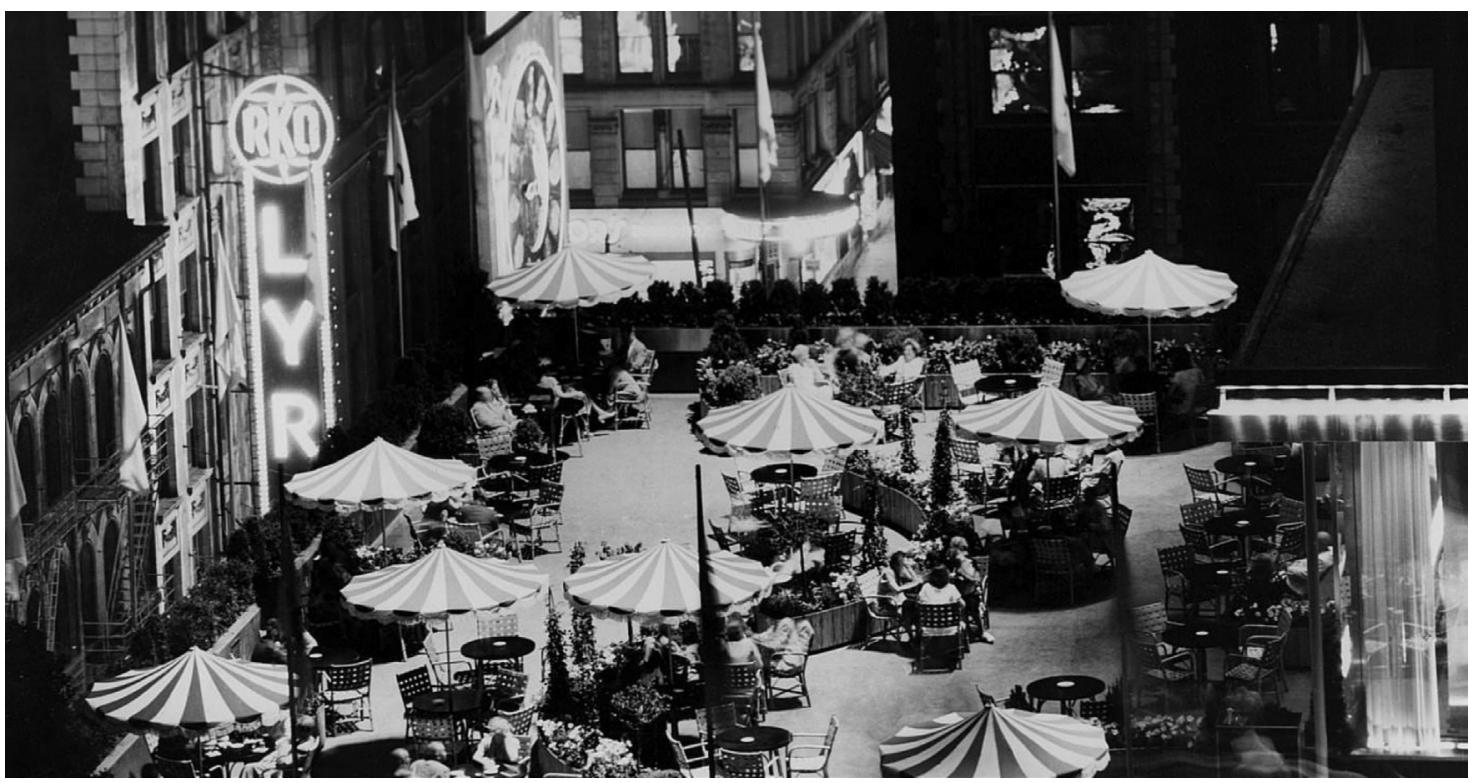

4. Vista nocturna de la terraza panorámica de la octava planta del Terrace Plaza Hotel. Cincinnati (fotografía: Ken Rarich). Fuente: $<$ http://www.som.com/projects/terrace_plaza_hotel> (fecha de consulta: 21-09- 2019)

estudió la inclusión de vegetación tanto en el interior como en el exterior de las terrazas. Ambas azoteas albergaron el diseño de un contorno verde donde la vegetación serviría tanto de linde como de primer término visual desde las terrazas hacia el skyline de Cincinnati.

En atención a la idea de un diseño integrado, la propuesta resultó un hotel de 12 plantas, emplazado sobre 7 niveles de comercio, que formó parte de un edificio mixto de 19 alturas en total [5]. Si bien la imagen fue la de un volumen sólido recubierto de tablillas de ladrillo, la intervención mantuvo rasgos de «levedad», con la inclusión del cristal como límite hacia las terrazas y en el perímetro de la planta baja. El interés por la exploración sobre el juego visual a través del vidrio prosperó con la creación de escenas atractivas en el
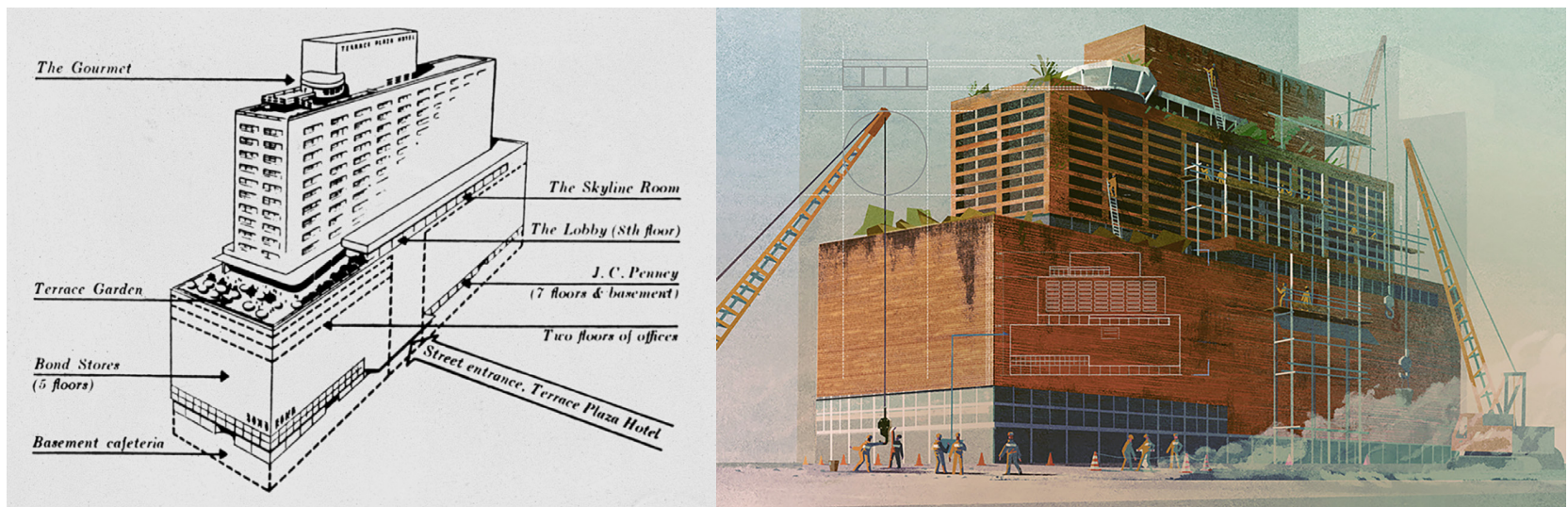

5. (Izq.) Representación de la localización y la conexión de los espacios en el Terrace Plaza Hotel. Fuente: National Register of Historic Places Registration Form (2017, junio). United States Department of the Interior, National Park Service, Cincinnati. p. 57 (fotografía: SOM) <http://cincinnatipreservation.org/ wp-content/uploads/2018/01/Terrace-Plaza-NR-Nomination-June-2017> (fecha de consulta: 01-07- 2020). (Der.) Ilustración del Terrace Plaza Hotel por Matthew Lyons. Fuente: <https://www.cincinnatimagazine.com/citywiseblog/what-will-come-of-the-terrace-plaza-hotel/> (fecha de consulta: 01-07- 2020) 
espacio interior a pie de calle. El edificio sacó partido de los escaparates de los grandes almacenes ${ }^{11}$.

Tanto el equipo de SOM como los consultores del encargo del Terrace Plaza Hotel, mantuvieron y desarrollaron los criterios que aplicaron en este edificio. Numerosos fueron los proyectos de posguerra de Skidmore, Owings \& Merrill que así lo demuestran y que con el tiempo han resultado modelos de la arquitectura moderna. El Manhattan House (1947-1951), aprovechó la cubierta como solárium y explotó las terrazas de sus apartamentos como extensiones hacia la calle; la Lever House (1950-1952), dispuso el comedor colectivo en la cubierta del volumen bajo que se habilitó como terraza hacia Park Avenue; el Manufacturers Trust Company (1953-1954), ajardinó la azotea que acompañó a las salas ejecutivas, juntas de reunión y comedores privados alineados a Fifth Avenue y el Pepsi Cola Company (1958-1959), que prolongó los comedores de los directivos de la empresa en la terraza de su cubierta. En todos los casos se insistió en proliferar las relaciones en cotas elevadas y se favorecieron las visuales del edificio hacia su contexto próximo.

\section{Relaciones arriba, abajo y alrededor}

En Cincinnati, el diseño del hotel fue revolucionario en cuanto a la flexibilidad práctica que lo caracterizó, a la distribución de sus espacios, y, sobretodo, a las novedosas relaciones que entre ellos se propiciaron. La entrada se situó a un tercio del camino a lo largo de la West Sixth Street hacia Vine Street. Los 28 pies $(8,53 \mathrm{~m}$.) del ancho del acceso resultaron de compartir el paso hacia el hotel con las dos tiendas por departamentos, Bond y J. C. Penney, que ocuparon los primeros niveles junto a un grupo de oficinas. Desde el nivel de la calle partieron múltiples baterías de elevadores automatizados que conectaron a las plantas del edificio. La organización programática se articuló con eficiencia en atención a los desplazamientos verticales dentro del prisma. El recibidor principal fue elevado a la planta octava [6]. Esta cota de implantación del vestíbulo fue el verdadero nivel de distribución de la propuesta; 4 de los 8 ascensores vincularon las habitaciones, 1 la Gourmet Room y el resto fueron para servicios.

El Terrace Plaza Hotel se aproximó al modo en que Raymond Hood abordó dos proyectos teóricos tras sus planteamientos para «ciudad de torres»: «"Una ciudad bajo un solo techo" (1931), el primero de estos proyectos, se ha basado en el principio de que la concentración en una zona metropolitana [...] es una situación deseable» (Koolhaas, 2004/1978: 174, 175) ${ }^{12}$. Las circunstancias urbanas del hotel -situación en el centro de la ciudad, normativas locales de implantación, base de almacenes comerciales, circuito de espacios culinarios, extensión de los interiores hacia las azoteas- promovieron el incremento de los enlaces y de los movimientos internos del edificio.

El protagonismo del tránsito en dirección vertical concertó la conexión de los ámbitos colectivos a través de ascensores de alta velocidad. Los elevadores unieron el acceso, el vestíbulo principal y los espacios gastronómicos. Se tejí una red -entre amenidades, antesalas, recintos y obras de arteque impulsó la interacción en sus zonas de ocio y diferenció el interior del edificio respecto al de sus coetáneos. El juego entre el arriba y el abajo se completó con el cruce en horizontal hacia las terrazas. Las posibilidades de entrelazamiento en ambos sentidos prosperaron la valía del planteamiento. Los conceptos de levedad, rapidez, exactitud, visibilidad y multiplicidad completaron la propuesta material (Calvino, 2008: 13) ${ }^{13}$.

Del mismo modo, muchas de las singulares ventajas reconocidas por el American Institute of Architects (AIA) sobre el Rockefeller Center en 1969, fueron recogidas en la concepción del Terrace Plaza Hotel. El éxito de la intervención en el Midtown dependió de la interrelación entre los edificios y de la coordinación del espacio arriba, abajo y alrededor. El desarrollo conformó un grupo de proyectos independientes que han coexistido hasta nuestros días en el mismo lugar. El conjunto respondió a una agrupación de varias propuestas en simultáneo. La obra consistió en sacar ventaja del vínculo entre diferentes actividades superpuestas en un único emplazamiento y de la articulación de los volúmenes alrededor de un área común al aire libre (Parga, 2018: 46). El diseño del Rockefeller Center ofreció una incorporación articulada al planeamiento urbano, fue una ejemplar composición de volúmenes construidos delineando los límites del proyecto e integrando «en y entre» edificios, grandes comercios y plazas. La solución proyectual fue uniforme y se convirtió en una lección sobre el uso de la tierra, con la habilidad de hallar amplios espacios y áreas al aire libre para el entretenimiento colectivo. Así, por su parte, el encargo del Terrace Plaza Hotel consideró estos logros. El estudio exhaustivo de las regulaciones habilitó el uso de ámbitos en altura al aire libre. Las terrazas 
ofrecieron las ventajas de localizaciones impensadas hasta el momento (Calvino, 2001: 55, 58) ${ }^{14}$. El proyecto de espacios colectivos con paredes acristaladas en niveles elevados produjo una serie de ambientes en relación que rompieron las convenciones habituales de hostelería. El Terrace Plaza Hotel fue uno de los primeros hoteles de arquitectura moderna en Estados Unidos, mostrándose deudor de los principios que pautaron el Rockefeller Center en Manhattan. El conjunto de Cincinnati fue sucesor del interés por interpretar los flujos peatonales; así como partidario por acoplar las circulaciones y optimizar sus conexiones. Ambas soluciones plantearon usos inexistentes en cotas inadvertidas para el momento, resultando proyectos vitales para la ciudad y para sus ciudadanos, tan viables hoy como cuando fueron construidos. El planteamiento del «edificio unidad» materializó los objetivos de SOM difundidos por Owings en 1949.

Así se establece nuestro entorno. Somos independientes. Debido a nuestro tamaño, somos claramente identificables como una sola unidad importante. Tenemos individualidad. ¡Tenemos carácter! Nuestro edificio de oficinas es un volumen rectangular simple y claro que se eleva desde un pedestal o base, libre de obstrucciones en todos los lados, lo que garantiza a perpetuidad, la luz, el aire y las vistas ${ }^{15}$.

El equipo SOM mantuvo la línea tanto en el desarrollo de la obra de Cincinnati, como al emprender el proyecto en el centro de Chicago. Las expectativas del edificio ideal parecían consolidarse y sentarían base para la serie de obras emblemáticas que realizaría la firma en años sucesivos. En el Terrace Plaza Hotel un volumen bajo restituiría el perímetro en los primeros niveles. La planta baja daría paso simultáneo a la clientela de los grandes almacenes y a los huéspedes del hotel; mientras que el plano elevado de su cubierta, a modo de balcón sobre su entorno, resultaría punto de inflexión a la superposición de actividades en una única propuesta. El edificio mixto respondería al diseño total y se multiplicaría en recintos idóneos para la integración del arte en sus espacios.

\section{El papel de la obra de Calder, Steinberg, Davis y Miró}

El Terrace Plaza fue apreciado como la primicia más exitosa de colaboración entre arte y arquitectura en un hotel moder-

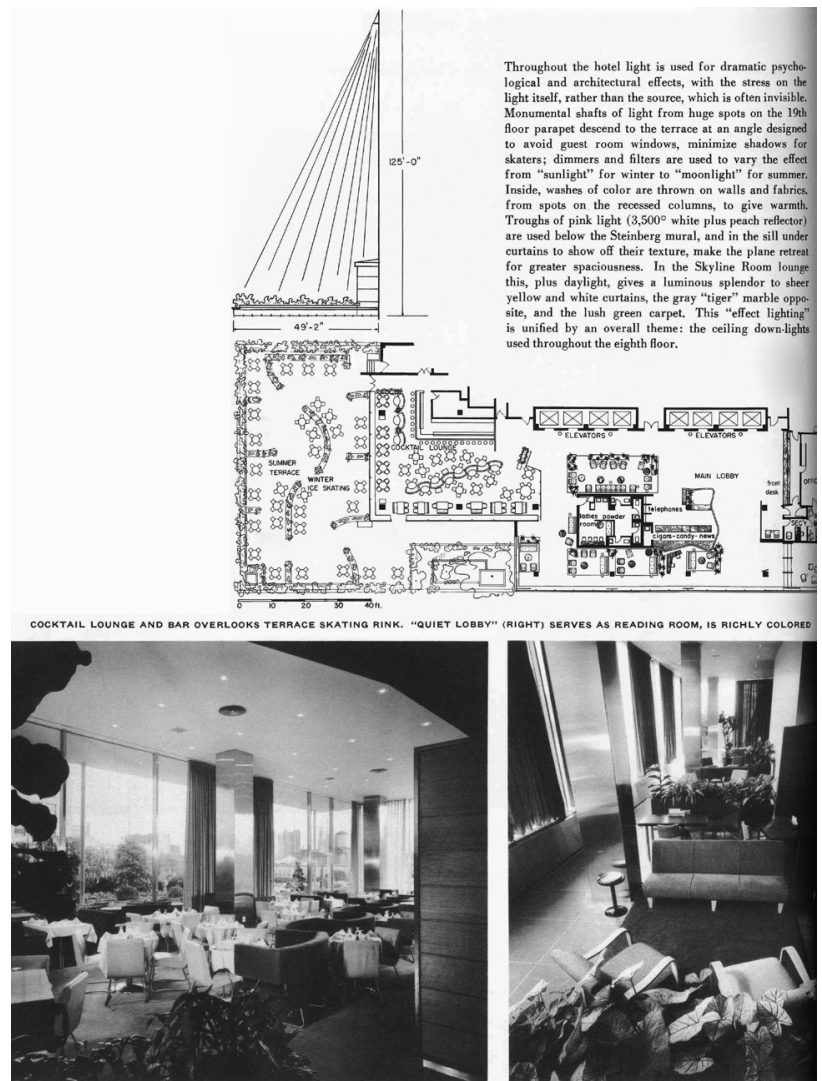

6. Octava planta. Fuente: «Cincinnati's Terrace Plaza» (1948, diciembre), Architectural Forum, Nueva York, p. 86 (fotografías: Ezra Stoller, Pictorial Services)

no. La invitación a participar para Calder, Steinberg, Davis y Miró manifestó la consideración de sus trabajos como proyección de la imagen del hotel al público por parte de la propiedad y de los arquitectos; se confió en el binomio cultura y comercio como aspecto importante del planteamiento ${ }^{16}$. La solución del Terrace Plaza Hotel, además de cuidar su configuración formal y de diseño global del conjunto de sus componentes, incorporó numerosas expresiones artísticas; sumó escultura en movimiento, pintura en murales, instalaciones visuales, tapices, tejidos, diseños geométricos para el mobiliario de madera laminada y paisajismo para el verde de los jardines. La intención de Emery para sus desarrollos comerciales fue la de lograr «obras unificadas», desde el diseño arquitectónico hasta los detalles de uso cotidiano; entendió que el arte aportaba prestigio y que era esencial integrarlo en los nuevos edificios. Emery, como presidente del Museo de Arte de Cincinnati, fue excepcionalmente activo en la pro- 

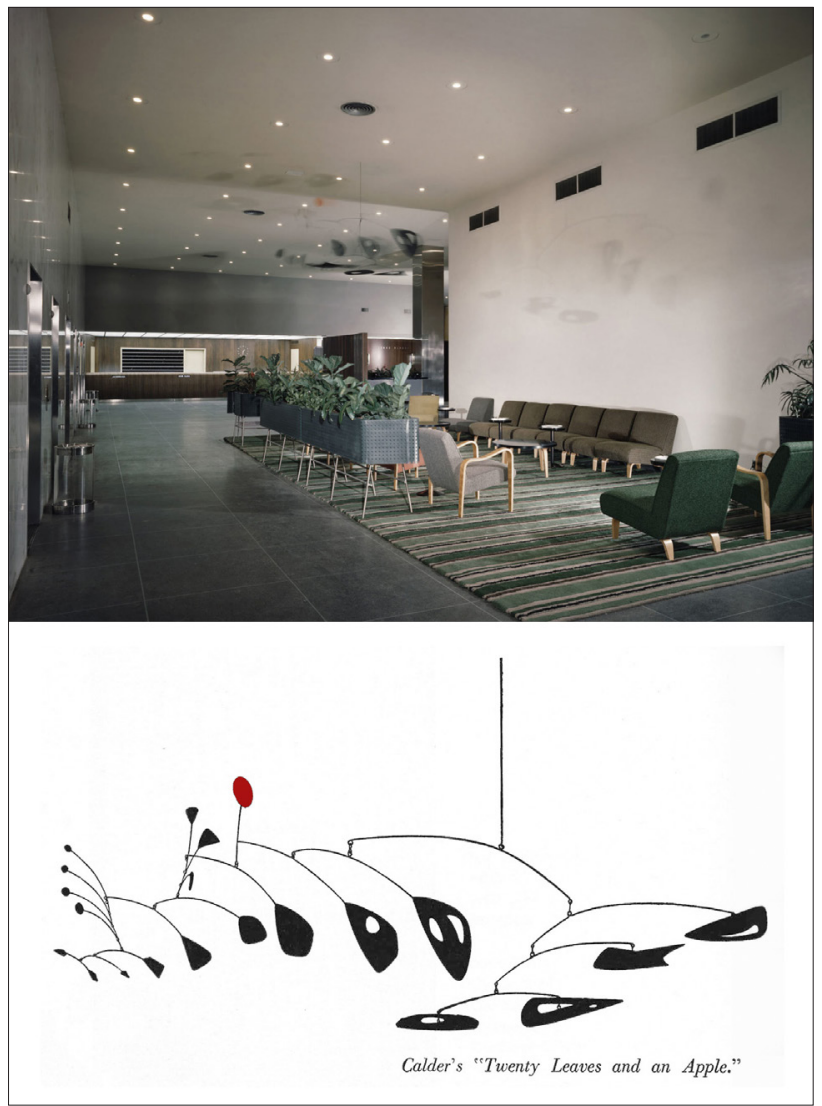

7. Vestíbulo de la planta octava con el móvil de Calder y la pared blanca donde se proyectan las sombras de sus movimientos. Fuente: "Cincinnati's Terrace Plaza» (1948, diciembre), Architectural Forum, Nueva York, p. 84. (fotografías: Ezra Stoller, Pictorial Services)

moción del trabajo de artistas contemporáneos, su proceder se convirtió en una inversión de marketing que impulsaría el vínculo entre el arte corporativo y la arquitectura moderna.

El equipo de SOM encargó a Alexander Calder $^{17}$ la creación de un móvil para el vestíbulo principal de la octava planta, obra que el artista tituló Twenty Leaves and an Apple. En los esquemas iniciales presentó un grupo de hojas grandes y bajas de color rojo, amarillo, azul y blanco que combinarían con el verde de las plantas, el mármol del plano de acceso a los ascensores y los tejidos de colores de los muebles y alfombras; finalmente, todas las «hojas» terminaron siendo negras en contraste con una «manzana» circular de color rojo brillante. El trabajo de Calder se instaló frente al grupo de elevadores, próximo a la sala de espera, bajo uno de los dispositivos mecánicos de ventilación para que el aire lo mantuviera en movimiento; al mismo tiempo, las luminarias se posicionaron para crear sombras sobre la pared blanca del recibidor. De este modo, el despliegue de las oscilaciones de la obra de Calder se vería proyectado en cambiantes figuras e imágenes sobre la superficie limpia de la sala, variando a cada instante el aspecto del doble espacio de bienvenida. El móvil se convirtió en fuente de novedosos efectos para el vestíbulo del hotel y la antesala de su restaurante principal, el Skyline Room [7].

El restaurante principal, situado a ocho plantas sobre la calle y cuyos comedores se prolongaron hacia la terraza ajardinada de ese nivel, albergó el mural realizado por Saul Steinberg ${ }^{18}$. El artista sumó a los atributos del espacio gastronómico la propuesta de un mural de 16 pies $(4,87 \mathrm{~m}) \mathrm{x}$ 100 pies $(30,48 \mathrm{~m})$ en el que representó puntos significativos y escenas imaginarias de la vida de Cincinnati. Para ello Steinberg programó su paso por Cincinnati en 1947; durante su visita conoció el restaurante aún en construcción, observó el entorno del hotel, tomó fotografías y adquirió postales que llevaría consigo como referencia de su vuelta por la ciudad. Al regresar a Nueva York, alquiló un amplio estudio y creó diez secciones de lienzo de 10 pies (3,04m.), que luego uniría en una única pieza. Propio de su estilo de ilustración, utilizó principalmente tinta negra sobre fondo blanco, a la que adicionó algunos tonos de marrón, gris y amarillo. A principios de marzo de 1948, envió los lienzos a Cincinnati; que más tarde instalaría con la ayuda de su amigo, el escultor arquitectónico y muralista italiano, Costantino Nivola. Tras el montaje definitivo, Steinberg retocó y agregó algunos detalles, también manifestó que hubiera preferido trabajar directamente en la pared ${ }^{19}$. El equipo de arquitectos veló en todas las etapas del diseño por acoplar con esmero el trabajo de los artistas al carácter de los espacios a los que se incorporaban [8].

El bar del restaurante principal, localizado entre los comedores y el jardín de la terraza de la planta octava, también contó con la inclusión del arte. El grupo de arquitectos pidió a Jim Davis la creación de un mural-escultura para el Cocktail Lounge. La obra de Davis fue el resultado de un corto periodo de su dedicación a las piezas compuestas por plásticos diáfanos y a los juegos de luz que lograba con ellas. Hacia 1946 había comenzado a hacer películas experimentales para capturar sus «abstracciones sinfónicas de color». Los plásticos transparentes de tres piezas de colores prima- 

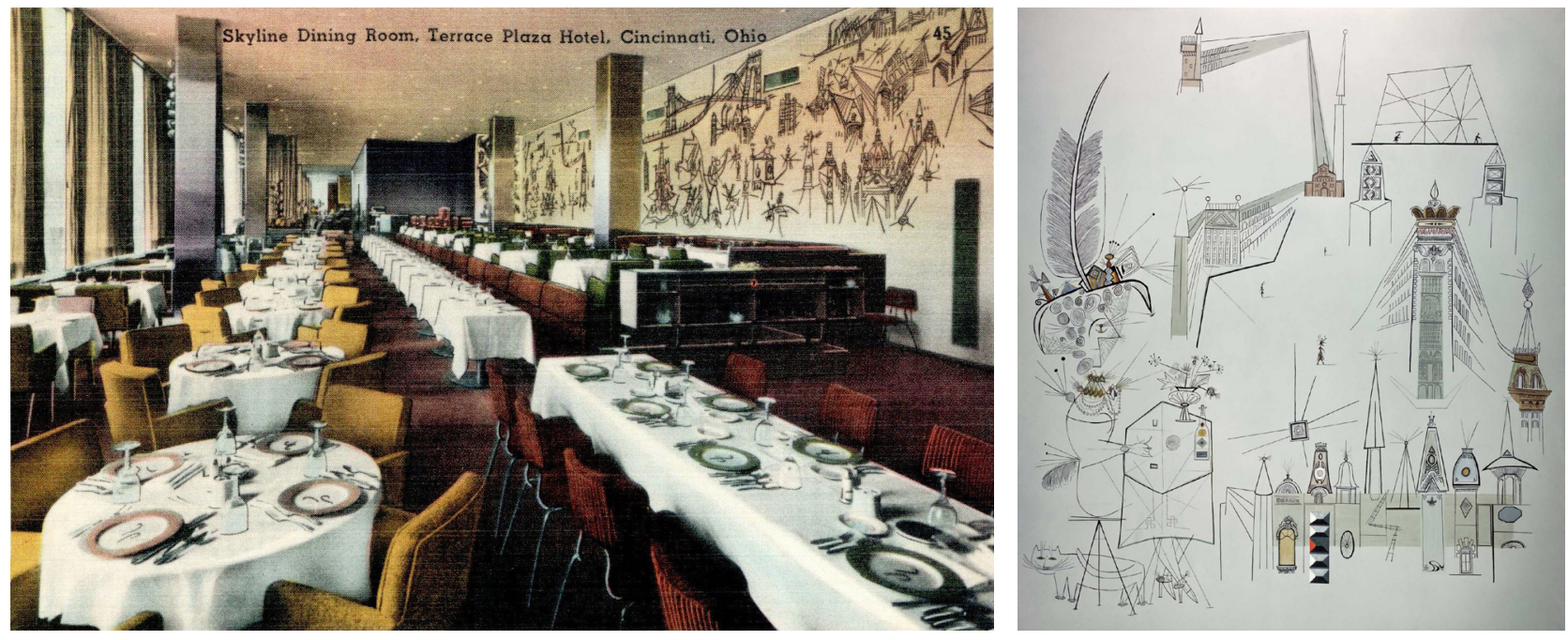

8. (Izq.) Skyline Room, Terrace Plaza Hotel, Cincinnati, con el mural de Steinberg instalado en 1948. Postal, c. 1950. Fuente: Archivos del Museo de Arte de Cincinnati. (Der.) Parte del mural de Saul Steinberg para el Terrace Plaza Hotel, actualmente expuesto en el Museo de Cincinnati. Fuentes: «Barroom Art in the Modern Manner», (1948, abril), Architectural Forum, Nueva York, p. 148; y en la página de la Fundación Saul Steinberg $<$ https://saulsteinbergfoundation.org/search-artwork/> (fecha de consulta: 01-07- 2020)

rios, junto a la iluminación artificial, contribuyeron a extender el efecto cambiante de las esculturas en toda la pared. El planteamiento de Davis promovió el salto al movimiento ilusorio creado con transparencias, formas y luz; semejante empleo del color dio lugar a superficies reavivadas que brindarían una atmósfera versátil junto a la vegetación del jardín de la terraza. Los tres objetos estáticos del mural sorprendieron con un conjunto caleidoscópico en constante variación de luz, color y movimiento; estas condiciones aportaron la singularidad al bar de rótula con el exterior.

La vigésima planta dio espacio al mural de gran formato sobre lienzo de Joan Miró ${ }^{20}$. La obra resultó ambiciosa para su tiempo, su presencia en la sala gastronómica definió el carácter del restaurante. El trabajo del artista completó el límite acristalado del espacio, se sumó a la panorámica de la ciudad que el recinto brindó a los comensales. La coIorida obra de Miró logró una atmósfera festiva; cualidad cuyo cuidado promovería la calidad del lugar donde la clientela disfrutaría de la buena mesa, factor determinante en la competitiva industria del servicio alimentario ${ }^{21}$. Los arquitectos y el arte aparecieron en el sector gastronómico, unidos a la aspiración de los propietarios por el proyecto total de sus comedores; velando por la buena comida, servicio y diseño [9]. Natalie de Blois, quien asumió el proyecto arquitectóni- co del hotel desde mediados de 1945, dedicó sus esfuerzos al estudio de los interiores de la planta 20. La Gourmet Room, no formó parte de la propuesta original; ella recuerda que se le pidió que diseñara varios esquemas para un pequeño comedor en la parte superior del hotel con la idea de construirlo en algún momento del desarrollo. Una vez incluido, el paso estrecho entre el ascensor y la Gourmet Room acentuó el efecto de descubrir las vistas urbanas que brindaba el salón circular del restaurante. En la estancia, sobre el único plano no acristalado del linde, se dispuso el mural de Miró, al que se acompañó con el sofá para banquetes y numerosos detalles diseñados expresamente para el comedor ${ }^{22}$

Tanto la documentación publicada por las revistas Architectural Forum como la información recopilada en los archivos de Avery Library's Drawings \& Archives de Columbia University en Nueva York sobre la obra posterior que impulsó Gordon Bunshaft desde la oficina de SOM New York, evidencian puntos en común sobre los criterios de promoción de la inclusión de piezas y el papel notable que se otorgó al arte y al diseño. Con el proyecto del hotel en Cincinnati se emprendió una perspectiva visionaria en la que la obra de artistas contemporáneos se integró en la arquitectura desde el inicio de su concepción. 


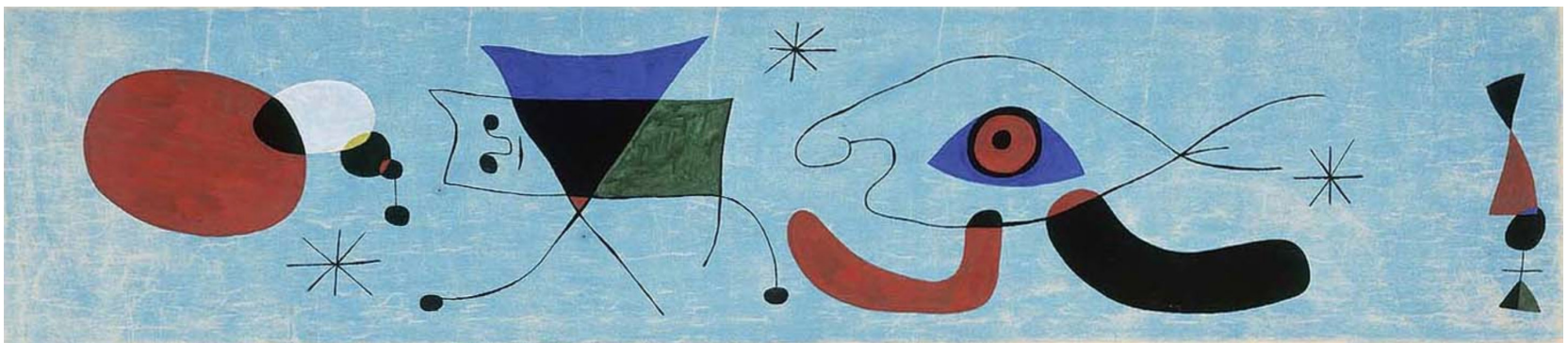

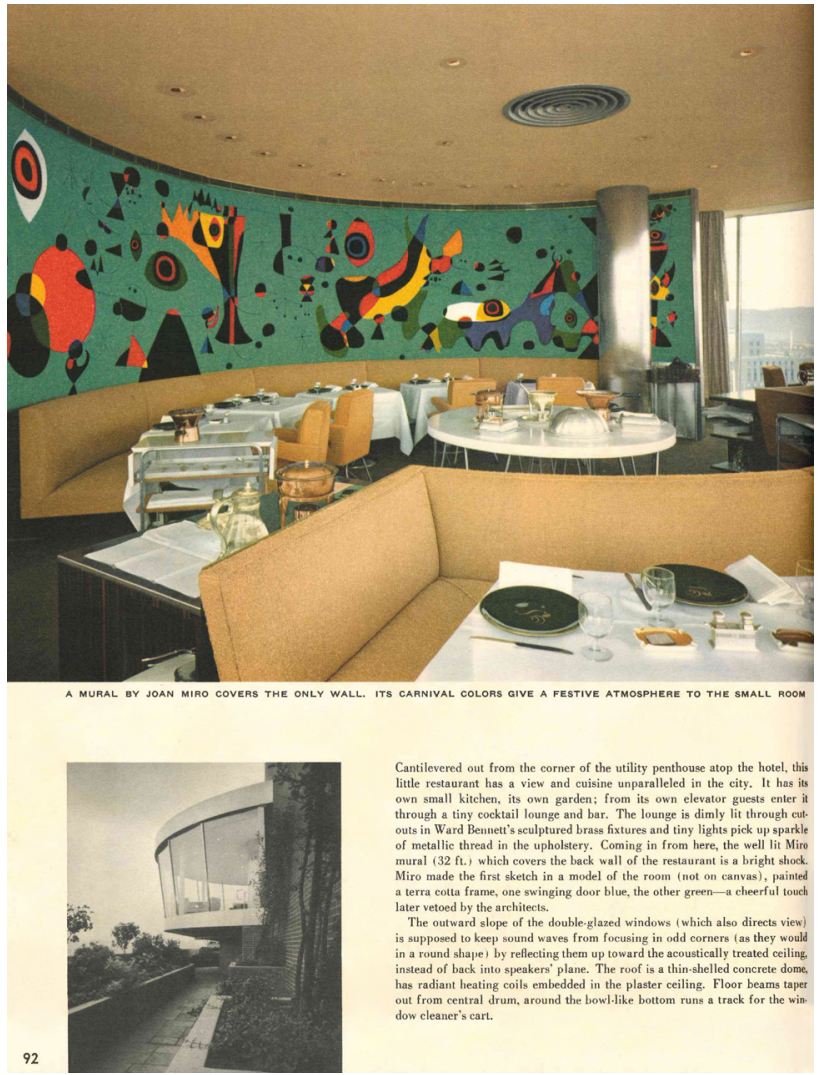

9. (Arriba) Boceto de Joan Miró para la pintura mural del Terrace Plaza Hotel, Cincinnati. Fuente: <https://miromallorca.com/es/collection/boceto-para-la-pintura-mural-del-terrace-plaza-hotel-de-cincinnati/> (fecha de consulta: 01-07-2020). (Abajo) Mural de Joan Miró en la Gourmet Room de la vigésima planta. Fuente: «Cincinnati's Terrace Plaza» (1948, diciembre), Architectural Forum, Nueva York, p. 92 (fotografías: Ezra StoIler, Pictorial Services)

\section{Atmósferas de arte y cristal}

La presencia de obras de arte junto a la disposición del cristal en los planos de conexión con las terrazas fueron los encargados de recrear y propiciar las vistas hacia la ciudad desde las estancias interiores del hotel en las plantas altas del edificio. La Gourmet Room garantizó la panorámica del exterior sin obstrucciones visuales, se consiguió acristalando el perímetro del techo blanco apoyado sobre las delgadas columnas de su límite [10]. La intención de ser mirador fue semejante a la de los ambientes de la planta octava. Allí, desde el móvil de Calder en el vestíbulo, el mural de Steinberg en el restaurante principal y un minucioso proyecto de entrelazamiento del conjunto de las salas, se procuró la comunicación fluida entre los interiores y la terraza en esquina.

En todos los casos, el formato de las intervenciones artísticas rompió el esquema convencional, las obras se encargaron de amplias dimensiones y abarcaron la totalidad de los planos de pared en los que se situaron. No fueron piezas sobrepuestas tras el diseño de los espacios, se pensaron e integraron en la arquitectura desde el inicio del proyecto. Con la intervención de cada artista, libres de expresarse con su propio lenguaje y medios materiales, se garantizó la proximidad al arte, la variedad de percepciones del espacio, la presencia del color y la mejora de la calidad de los ambientes de la propuesta arquitectónica.

Los recursos operativos de diseño, con la incorporación del móvil y los murales para los interiores del edificio, junto a la experimentación con el cristal y las nuevas tecnologías, evolucionarían en intervenciones posteriores de la firma. Más adelante, las obras de arte se desplazarían al umbral entre el interior y el exterior, pasarían a estar al aire libre; se acoplarían a los ámbitos próximos de cada edificio haciéndose presentes en la vida cotidiana de la ciudad. Los promotores, en su afán coleccionista, apoyaron y difundieron la relación entre arte y arquitectura en sus esferas de negocios. La concepción del Terrace Plaza Hotel resultó decisiva e influyente en la evolución de las directrices de diseño de la firma y de quienes le siguieron. El planteamiento del hotel se materializó en los años de un activo debate sobre 
la presencia del arte contemporáneo en la arquitectura, y en conocimiento de obras previas que lo llevaron a la práctica. En la década de los treinta se construyó el Rockefeller Center donde los arquitectos promovieron activamente la adición de esculturas y murales al conjunto de edificios (Krinsky, 1978: 144); también en Nueva York en 1939 los Pabellones de la Feria Mundial, proyectados por Gordon Bunshaft en los inicios de Skidmore \& Owings, incluyeron esculturas y murales de artistas autóctonos de los países a los que las muestras representaban. A la par de esta dinámica, en 1943, apareció el manifiesto Nine Points on Monumentality (Sert, Léger, Gideon, 1944; Gideon, 1958: 48-51), con una serie de ideas a las que el Terrace Plaza se aproximó en su concepción. El proyecto del hotel respondió con acierto a las premisas de que los edificios no pueden concebirse de forma aislada, deben ordenarse en su entorno y con la voluntad de la creación integral; las obras han de aunar los esfuerzos del planificador, del arquitecto, del pintor, del escultor, favoreciendo la estrecha colaboración de todos los partícipes; los procesos de proyecto y obra han de aventajarse de los materiales modernos y de las nuevas posibilidades técnicas.

La relación entre SOM, el arte, los nuevos materiales y el avance tecnológico se ha prolongado a lo largo de toda su trayectoria. La aproximación de este artículo al vínculo entre arte y arquitectura podría continuarse con el seguimiento de los proyectos que le sucedieron al hotel. Resulta posible hilar el trabajo de Calder, Steinberg y Miró, al de Bertoia, Dubuffet, Noguchi y Moore en alianza con las intervenciones de SOM New York. El Manufacturer Trust Company (19531954) retomó el vestíbulo elevado, con incorporación de móvil y mural de Harry Bertoia. El Chase Manhattan Bank (1961) incluyó un Calder en su interior, un Dubuffet en su plaza y un Noguchi como jardín de agua en su exterior próximo. El Lincoln Center (1965), de igual modo, en sus áreas al aire libre, incorporó esculturas de Moore y Calder. El Marine Midland Bank (1967), en su frente hacia Broadway contó con una llamativa escultura de Noguchi.

Las obras de arte que Emery encargó para el Terrace Plaza Hotel tuvieron una proyección duradera. Su influencia fue notable en el propio edificio, en la continuidad de la labor
From the tiny Gourmet restaurant, 56 exclusive guests can view the city
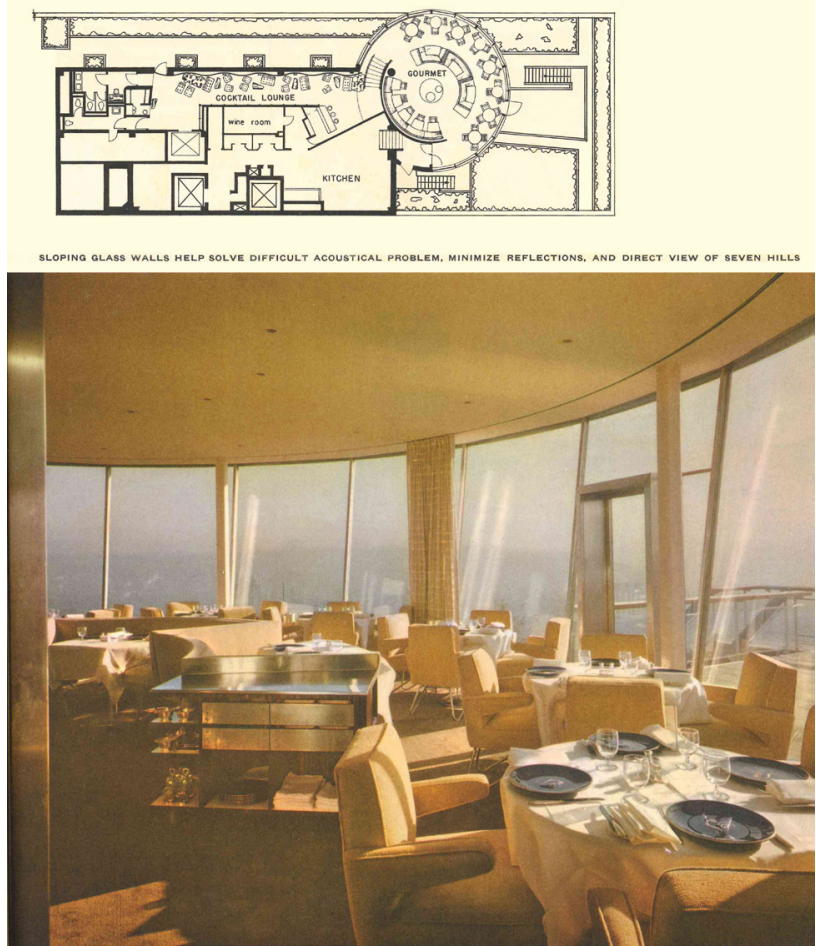

10. Cerramiento acristalado de la Gourmet Room en la vigésima planta. Vista panorámica sobre Cincinnati. Fuente: "Cincinnati's Terrace Plaza» (1948, diciembre), Architectural Forum, Nueva York, p. 93 (fotografías: Ezra Stoller, Pictorial Services)

de SOM, en el mundo del arte y en la arquitectura moderna. El arte se convirtió en una herramienta para atraer la lealtad de los clientes y mejorar la imagen pública de las empresas que lo promovieron; esta estrategia resultó representativa del carácter de la América corporativa. SOM impulsó la valía de la inclusión de cada pieza, Gordon Bunshaft, a lo largo de toda su carrera, influyó en las decisiones de la firma y de los clientes para que el arte formara parte de sus edificios. En el hotel de Cincinnati, Natalie de Blois garantizó la calidad de los espacios, elementos y detalles que encuadraron el trabajo de los artistas, consolidando la deseada relación entre arte y arquitectura contemporáneos. 


\section{Notas}

1 SOM. Firma norteamericana de arquitectos formada por Louis Skidmore, Nathaniel A. Owings y John O. Merrill (1939-presente). Llegaron a ser un grupo de trece socios, además de los tres fundadores, se sumaron William S. Brown, Gordon Bunshaft, Robert W. Cutler, J. Walter Severinghaus, John B. Rodgers, William E. Hartmann, Elliott F. Brown, James W. Hammond, Walter A. Netsch Jr., Edward J. Mathews. El equipo ofrecía servicios integrales de programación, planeamiento, proyecto arquitectónico, diseño interior, ingeniería y supervisión de obra. Actualmente son un colectivo de arquitectos, diseñadores, ingenieros y planificadores que mantienen el enfoque colaborativo de su trabajo; el equipo interdisciplinario es internacional.

2 «SOM. Terrace Plaza Hotel». En: <http://www.som.com/projects/terrace_plaza_hotel> (fecha de consulta: 21-09- 2019). «The Terrace Plaza was the first hotel designed by SOM and one of the first modern hotels in the United States. Its lobby, located on the eighth floor, was reached by express elevators from the street entrance. Two department stores originally occupied the first seven floors. The top floor, home to a small gourmet restaurant, offered panoramic views of the city. SOM designed the restaurant's interiors and accessories, and commissioned Joan Miró to design a mural as a focal point for the space. Other artists' works were included as part of the architectural design; a Calder mobile hung in the lobby, and a Saul Steinberg mural adorned the main restaurant». Esta y todas las sucesivas citas en inglés han sido traducidas por la autora del artículo.

3 Natalie Griffin de Blois (Nueva Jersey, Estados Unidos 1921-Chicago, Estados Unidos 2013). Arquitecta por Columbia University en 1944; año en que se incorporó a SOM. Tras ganar una beca Fullbright para estudiar en la Escuela de Bellas Artes de París (1951) regresó a trabajar en la firma norteamericana. Allí colaboró con William S. Brown, Gordon Bunshaft y Robert W. Cutler como responsable del diseño, programación, presentación, delineación, interiorismo y coordinación de la consultoría de estructuras e instalaciones.

4 William E. Hartmann, quien se unió al equipo de SOM en 1945, describió el proyecto del Terrace Plaza Hotel como 'asombroso' en la entrevista que concedió para el Department of Architecture The Art Institute of Chicago para su colección de historia oral.

5 Gutheim, Frederick (1957), 1857-1957. One hundred years of architecture in America. Reinhold Publishing Company. Library of Congress Catalog Card No. 57-11223. Nueva York, p. 96.

6 "Cinema \& Hotel in Sao Paolo» (1949), The Architectural Review, n. ${ }^{12}$ 2, Londres, pp. 350-351.

7 Informe de nominación del Terrace Plaza Hotel al Registro Nacional de Edificio Históricos. En: <http://cincinnatipreservation.org/wp-content/uploads/2018/01/ Terrace-Plaza-NR-Nomination-June-2017> (fecha de consulta: 01-07- 2020).

8 Hunt-Encyclopedia of American Architecture, «Rockefeller Center», p. 263.

9 "Cincinnati's Terrace Plaza» (1948, diciembre), Architectural Forum, Nueva York, p. 83. «The most striking design innovation, which grew naturally out of the store base, was lifting the hotel lobby to the eight floor level. By taking all the required zoning set-backs at this level, the designers were able to create an attractive roof-top plaza adjoining the lobby, lifted above traffic and street noises and equipped for summer dinning, winter-time skating".

10 «Pickaback office building, rides a Chicago bus terminal with a roof-top park - a sequel to the Terrace Plaza Hotel» (1949, agosto), Architectural Forum, Nueva York, pp. 70-71. El discurso de Owings 'The Ideal Office Building. A «dream boat» speech by Architect Owings which is materializing in the Chicago Greyhound project' se reprodujo al final del artículo; pp. 75, 164, 168. «The fourth floor level of the entire site we will make an outdoor park with real grass, trees and pools and restaurants. Our office building and entrance is here. Escalators take us from the car parking levels to this oasis of green", p. 164.

11 Este recurso recordaba la vitrina acristalada que introdujo el Eastern Air Lines Building en el Rockefeller Center y que Gordon Bunshaft, arquitecto director de la oficina SOM New York, comenzaría a explotar hacia el inicio de la firma con el diseño del pabellón de Venezuela en la Feria Mundial de Nueva York de 1939.

12 Koolhaas, Rem (2004/1978), Delirio de Nueva York. Un manifiesto retroactivo para Manhattan, traducción: Jorge Sainz, Gustavo Gili, Barcelona, 2004, pp.174, 175. Idea recogida en el apartado «Premonición» en el capítulo «El talento de Raymond Hood»: «La tendencia se orienta hacia unas comunidades relacionadas dentro de la ciudad: comunidades cuyas actividades queden restringidas a determinadas zonas en las que el tráfico no tenga necesidad de desplazarse hasta calles lejanas para recoger suministros y encargos"

13 Calvino, Italo (2008), Seis propuestas para el próximo milenio, Ediciones Siruela, Madrid, p. 13. Probablemente uno de los esquemas sobre los que trabajó Calvino en la preparación de sus conferencias para la «Charles Eliot Norton Poetry Lectures" nos de pistas sobre el atender a lo que ocurre «entre» las cosas, más que en las cosas mismas. «El 8 de mayo de 1985 escribe: habiendo acabado (?) La levedad | habiendo esbozado Multiplicidad | habiendo ya escrito extensamente sobre The art of begining and the art of concluding | manteniendo como punto necesario visible/invisible | -singularis/universalis | trato de puntualizar: | otras cuestiones podrían ser: | rapidez (quickness) la nada los otros | concisión | exactitud-geometría".

14 Calvino, Italo (2001), Palomar, Ediciones Siruela, Madrid, pp. 55, 58. «Desde la terraza (...) Nada de esto puede ser visto por quien mueve sus pies o sus ruedas sobre el pavimento de la ciudad. E inversamente, desde aquí arriba se tiene la impresión de que la verdadera corteza es ésa, desigual pero compacta (...) porque es tanta y tan rica y variada la visión de superficie que basta y sobra para saturar la mente de informaciones y significados».

15 «Pickaback office building, rides a Chicago bus terminal with a roof-top park - a sequel to the Terrace Plaza Hotel» (1949, agosto), Architectural Forum, Nueva York, pp. 70-71. El discurso de Owings «The Ideal Office Building. A «dream boat» speech by Architect Owings which is materializing in the Chicago Greyhound project» se reprodujo al final del artículo; p.75, 164, 168. «Thus our environment is established. We are self-contained. Because of our size we are clearly identifiable as a single important unit. We have individuality. We have character! Our office building is a clear simple rectangular shaft rising from a pedestal or base, free of obstructions on all sides, permitting in perpetuity, ligh, air and view", p. 164.

16 Gordon Bunshaft lo procuró diez años antes en los proyectos para los pabellones de la Feria Mundial de Nueva York de 1939. A posteriori, como responsable de SOM New York y aficionado a la labor artística, consiguió, mantuvo e intensificó la relación entre el arte y la arquitectura en los espacios que concibió.

17 Alexander Calder (Pennsylvania, Estados Unidos 1898-Nueva York, Estados Unidos 1999). Escultor, conocido por sus innovadores móviles. Una de sus obras más importantes fueron las Nubes flotantes (1952-1953), instaladas en el Aula Magna de la Universidad Central de Venezuela. Las piezas las diseñó especialmente combinando arte, arquitectura y tecnología.

18 Saul Steinberg (Râmnicu Sarat, Rumania 1914-Nueva York, Estados Unidos 1999). Caricaturista e ilustrador. Culminó estudios de arquitectura en Milán. Trabajó para The New Yorker por más de cincuenta años. Participó en la exposición Fourteen Americans, The Museum of Modern Art of New York.

19 Smith, Joel (2006), Saul Steinberg. Illuminations, Yale University Press, New Haven y Londres, p. 46. 
20 Joan Miró i Ferrà (Barcelona, España 1893-Palma de Mallorca, España 1983). Pintor, escultor, grabador y ceramista, considerado uno de los máximos representantes del surrealismo. En sus obras reflejó su interés en el subconsciente, en lo «infantil» y en la cultura de Catalunya. También se le asocia al arte abstracto por su estilo de formas estilizadas e imaginarias.

21 "A look at dining rooms» (1956, febrero), Architectural Forum, Nueva York, p.134-137. Entre la introducción y el apartado «Simple y abierto", se alude al caso de los restaurantes del Terrace Plaza Hotel, donde un modo de lograr la definición y simplicidad de los espacios de sus salas fue a través del apoyo del arte.

22 Informe de nominación del Terrace Plaza Hotel al Registro Nacional de Edificio Históricos. En: <http://cincinnatipreservation.org/wp-content/uploads/2018/01/ Terrace-Plaza-NR-Nomination-June-2017> (fecha de consulta: 01-07-2020), p. 24.

\section{Bibliografía}

ADAMS, Nicholas (2005), «Working for SOM. Conversation with Natalie de Blois» Casabella, Milán, pp. 104-110.

«A look at dining rooms» (1956, febrero), Architectural Forum, Nueva York, pp. 134-139.

«Barroom Art in the Modern Manner» (1948, abril), Architectural Forum, Nueva York, pp. 148-150.

BITTERMANN, Eleanor (1952), Art in Modern Architecture, Reinhold Publishing Corporation, Nueva York.

BLUM, Betty J. (2004), «Oral history of Natalie de Blois» interviewed by Blum, Architects Oral History Project, The Ernest R. Graham Study Center for Architectural Drawings, Department of Architecture, The Art Institute of Chicago, Chicago.

«Cincinnati's Terrace Plaza» (1948, diciembre), Architectural Forum, Nueva York, pp. 81-96.

«Cinema \& Hotel in Sao Paolo» (1949), The Architectural Review, n. ${ }^{12}$, Londres, pp. 350-351.

DE BLOIS, Natalie (2004, junio), «Natalie de Blois Interviewed by Detlef Mertins», Chicago, en (2006) SOM Journal 4, Nueva York, pp.132159.

DE BLOIS, Natalie (2008, noviembre), «Letter to Nicholas Adams», en Terrace Plaza Hotel file. Cincinnati Preservation Association, Cincinnati, Ohio.

GIDEON, Sigfried (1957, abril), «Das Experiment S.O.M.», Bauen+Wohnen=Construction+habitation=Building+home:internationale Zeitschrift, Zúrich, pp. 109-114.

GIDEON, Sigfried (1958), Architecture you and me, Harvard University Press, Cambridge, Massachusetts.

GUTHEIM, Frederick (1957), 1857-1957. One hundred years of architecture in America. Reinhold Publishing Company. Library of Congress Catalog Card No. 57-11223, Nueva York, p. 96.

HARTMANN, William E. (1957, abril), "Die Organisation der Firma Skidmore, Owings \& Merrill», Bauen+Wohnen= Construction+habitation= Building+home: internationale Zeitschrift, Zúrich, pp. 115-117.

KOOLHAAS, Rem (2004/1978), Delirio de Nueva York. Un manifiesto retroactivo para Manhhatan, traducción: Jorge Sáinz, Gustavo Gili, Barcelona.

KRINSKY, Carol Herselle (1978), Rockefeller Center, Oxford University Press, Nueva York.

«National Register of Historic Places Registration Form» (2017, junio). United States Department of the Interior, National Park Service, Cincinnati. En: <http://cincinnatipreservation.org/wp-content/uploads/2018/01/Terrace-Plaza-NR-Nomination-June-2017> (fecha de consulta: 01-07-2020).

PARGA, Andrea (2018), Edificios que hacen ciudad. La arquitectura de Gordon Bunshaft para la gran manzana (1947-1967), Escuela Técnica Superior de Arquitectura de Barcelona, UPC, Barcelona. En: <http://hdl.handle.net/2117/113989-http://hdl.handle.net/10803/461407>.

«Penthouse Hotel for Cincinnati is built on two big stores and the premise that modern design and engineering are more important than hotel tradition» (1946, diciembre), Architectural Forum, Nueva York, pp. 100-108.

«Pickaback office building, rides a Chicago bus terminal with a roof-top park - a sequel to the Terrace Plaza Hotel» (1949, agosto), Architectural Forum, Nueva York, pp. 70-74, 164, 168.

SMITH, Joel (2006), Saul Steinberg. Illuminations, Yale University Press, New Haven y Londres.

«SOM. Terrace Plaza Hotel». En: <http://www.som.com/projects/terrace_plaza_hotel> (fecha de consulta: 21-09- 2019).

«Terrace Plaza revisited» (1956, agosto), Architectural Forum, Nueva York, pp. 131-133. 